\title{
Measurement and Analysis of Optical Characteristics of Silicon Solar Cell Using Integrating Sphere
}

\author{
P. S. Manoharan*, V. Shanmugapriya, P. Deepamangai \\ Department of Electrical and Electronics Engineering, Thiagarajar College of Engineering, India
}

Received July 4, 2019; Revised September 19, 2019; Accepted September 26, 2019

Copyright $@ 2019$ by authors, all rights reserved. Authors agree that this article remains permanently open access under the terms of the Creative Commons Attribution License 4.0 International License

\begin{abstract}
The aim of this paper is to analyze the optical parameters of solar cell materials using the integrating sphere. The optical parameters including reflectance, transmittance, absorptance and emissivity are measured for the samples $\mathrm{ZnO}$ with $0.025 \mathrm{M}$ concentration, $\mathrm{ZnO}$ with $0.05 \mathrm{M}$ concentration, $\mathrm{ZnO}$ with $0.1 \mathrm{M}$ concentration and $\mathrm{Cu} / \mathrm{Ti} / \mathrm{SiO}_{2}$ with $0.025 \mathrm{M}$ concentration. The transmittance and reflectance of the samples are calculated with respect to the wavelengths to find whether the samples absorb light of the portion of the solar spectrum. These optical characteristics are measured by using integrating sphere and this work will lead to the analysis of quality of material used for coating the photovoltaic cell in order to increase the conversion efficiency of photovoltaic system.
\end{abstract}

Keywords Absorptance, Emmisivity, Optical Efficiency, Photovoltaic, Reflectance, Transmittance

\section{Introduction}

In recent decades there have been an increasing interest in the use of renewable energy systems. Energy scenario plays a vital role in determining the socio-economic status of a country in the 20th century. Energy management becomes a fundamental problem for the growth and magnificence of any society [1]. Hence, it is necessary to optimize the energy resources. Of the available renewable energy resources, solar energy becomes most prominent in power generation due to its availability and reliability. It is necessary to extract maximum power from the photovoltaic cell to maintain the efficiency of power generation system. The Photovoltaic module is made up of photovoltaic (PV) cell. PV cell is made up of silicon based semiconductor materials. Electrical, optical and thermal characteristics of silicon materials are an important measure for the conversion efficiency [2, 3]. Hence, the solar industries are concentrated on quantification of material optical properties such as reflectance and transmittance usually measured between $300 \mathrm{~nm}$ and $1500 \mathrm{~nm}$. Reflectance properties in solar modules are the main factor for natural heating. An ideal silicon wafer reflects $35 \%$ of sunlight, losses will occur and hence conversion efficiency will be reduced [4]. TiO2 and $\mathrm{SiO} 2$ are most commonly used anti reflective coatings. Hence, suitable anti reflective coatings on silicon wafer is essential to reduce the loss of sunlight [5-8]. Also, the colours of the coatings are of major concern for maintaining conversion efficiency [9-13]. The optical transmittance is also an important characteristic of PV module. The performance of PV module may be affected by change in transmittance. Reflectance and transmittance are measured by different spectrophotometers such as goniophotometer, integrating spheres, etc. Goniophotometer is a photometric method which measures the total lumen, and it has some limitations such as high cost, calibration time is high and on lumen test. Integrating sphere measures the total luminous flux by calibrated standard lamp and the calibration time is less compared to goniophotometer [14]. Hence, in this work, reflectance and transmission characteristics of $\mathrm{PV}$ cell is measured by using integrating sphere for the samples $\mathrm{ZnO}$ with $0.025 \mathrm{M}$ concentration, $\mathrm{ZnO}$ with $0.05 \mathrm{M}$ concentration, $\mathrm{ZnO}$ with $0.1 \mathrm{M}$ concentration, and $\mathrm{Cu} / \mathrm{Ti} / \mathrm{SiO} 2$ with $0.025 \mathrm{M}$ concentration.

\section{PV Materials Used for Analysis}

The solar cell materials under study are zinc oxide samples of various concentrations. The specifications of the samples are listed in the Table 1. A laser beam is illuminated on the solar cell materials to find the different characteristics. The red or green laser beam are used and parameters can be quantified depending on the used beam. 
Table 1. Specification of PV materials

\begin{tabular}{|c|c|c|c|}
\hline S.No. & $\begin{array}{c}\text { Material under } \\
\text { test }\end{array}$ & $\begin{array}{c}\text { Concentrations } \\
\text { in } \mathbf{~ m m}\end{array}$ & $\begin{array}{c}\text { Annealing } \\
\text { temperature } \text { in }{ }^{\circ} \mathbf{C}\end{array}$ \\
\hline 1. & Zirconia fibre & - & - \\
\hline 2. & Stainless Steel & - & - \\
\hline 3. & Zinc oxide & 0.025 & 75 \\
\hline 4. & Zinc oxide & 0.075 & 110 \\
\hline 5. & Zinc oxide & 0.05 & 150 \\
\hline 6. & Zinc oxide & 0.1 & 150 \\
\hline 7. & Coloured fabrics & - & - \\
\hline
\end{tabular}

\section{Methodology}

The Illumia ${ }^{\circledR}$ pro 500-50, AA 805 10-100 integrating system has been used to test the specified materials. The set up within the integrating sphere has been modified for various characteristics measurement. There are two modes of measurements.

\subsection{Mode for Reflectance Measurement}

The reference beam is made incident through the reference beam port. The sample is placed in such a manner that the reference beam is incident on the sample under test. The $\mathrm{BaSo}_{4}$ coating of the integrating sphere makes all the reflected light contained within the sphere. Only a small fraction of the beam escapes through the reference port.

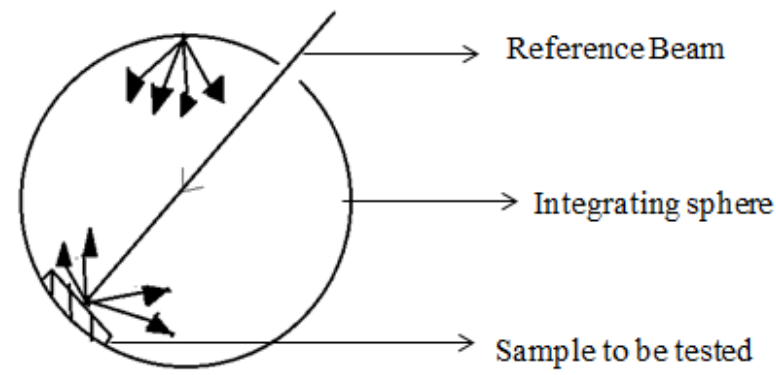

Figure 1. Mode of integrating sphere for reflectance measurement

The integrating sphere is coated with a diffuse coating. Specularly reflected light and the diffusely reflected light are randomized and the intensity is equally distributed over the sphere as shown in Figure 1. Measuring the intensity on each point of the sphere will lead to the same results. The diffusely reflected light is measured by making a small opening in the integrated sphere so that the specularly reflected light escapes from the sphere. The reflection measurement on the samples is normalized by the reflection of a white standard to obtain absolute reflectance of the sample.

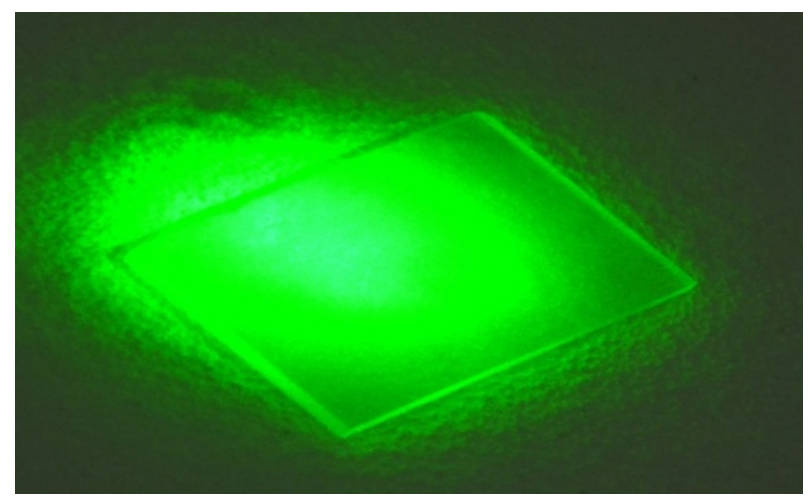

Figure 2. Integrating sphere set up for reflectancemeasurement

\subsection{Mode for Transmittance Measurement}

In transmittance measurement the sample is positioned in front of the entrance port of the beam. Specular absorbance can also be determined by placing a light trap material perpendicular to the entrance port. The specular light is escaped through a small opening within the integrating sphere. Measuring the intensity on each point of the sphere results the same.

Figure. 3 shows the mode for transmittance measurement. The radiation enters the sphere through the port facing the sample holder and hits the sample. The measurements are performed between 380 and $1700 \mathrm{~nm}$, covering the 92.7\% of the whole solar spectrum energy.

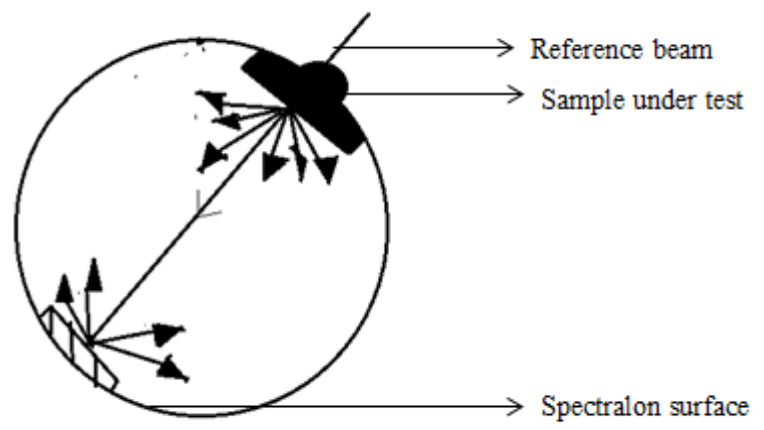

Figure 3. Mode of integrating sphere for transmittance measurement

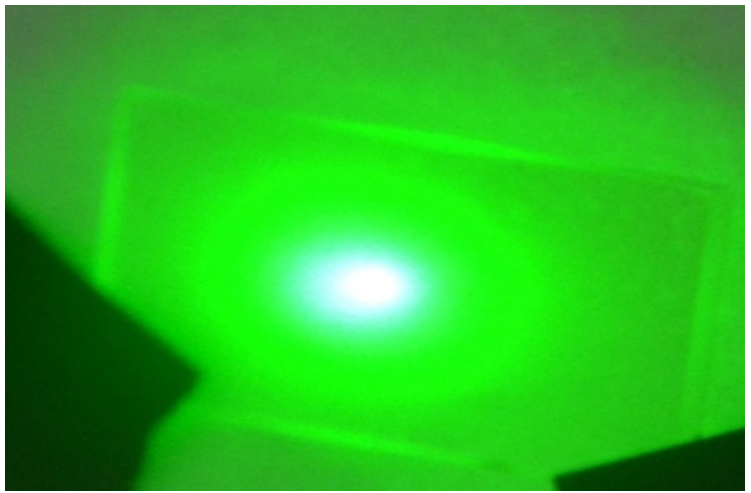

Figure 4. Integrating sphere set up transmittance measurement 
Figure.5 shows the various samples under test for various optical characteristics measurement.

The set up within the integrating sphere is modified as said in the two modes. Figure 4 shows the set up within the integrating sphere.

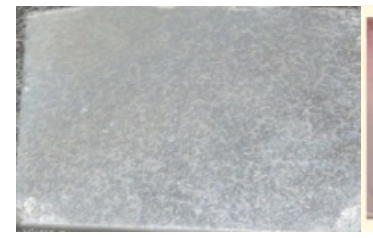

(a)

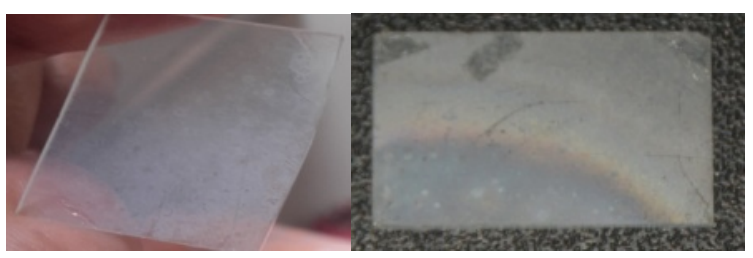

(c)

(d)

Figure 5. Solar cell materials (a) Zinc oxide with $0.025 \mathrm{~m}$ concentration (b) zinc oxide with $0.05 \mathrm{~m}$ concentration (c) Zinc oxide with $0.075 \mathrm{~m}$ concentration (d) Zinc oxide with $0.1 \mathrm{~m}$ concentration

\subsection{Measurement of Reflectance and Transmittance}

The reflection measurement on the samples is normalized by the reflection of a white standard to obtain absolute reflectance of the sample.

The reflectance is mathematically given by the (1),

$$
\% \text { reflectance }=\int \frac{E(\lambda) d(\lambda)}{E_{p h}(\lambda) d(\lambda)} \times 100
$$

Where,

$E(\lambda)$ - is the spectral radiance incident on the spectral sample,

$E_{p h}(\lambda)$ - is the spectral incident radiance of the integrating sphere.

Determination of the reflectance for directional irradiation of diffusely reflecting samples requires measurement of the radiation reflected into the whole hemisphere. This can be done with integrating spheres.
For the transmittance measurement, the sample is mounted on the front of the integrating sphere, so that all transmitted light was collected, that is the zeroth order and diffusely transmitted.

The transmittance is mathematically given by (2),

$$
\% \text { transmittance }=\int \frac{E_{\text {throu }}(\lambda) d(\lambda)}{E_{p h}(\lambda) d(\lambda)} \times 100
$$

where,

$E_{\text {throu }}(\lambda)$ - is the spectral radiance through the sample. Spectral absorbance $(\alpha)$ is the common logarithm of the ratio of incident to transmitted spectral radiant power through a material.

Absorbance is defined as $(\alpha)=1$ - (reflectance) (3)

The optical characteristics are calculated for some samples as given below:

1. ZnO sample with $0.025 \mathrm{~m}$ concentration

\%Transmittance $=16011.6 / 51674.1=30.9 \%$

\%Reflectance $=8503.8 / 51674.1=16.45 \%$

Absorbance $=1-0.164=0.836=83 \%$

Emissivity $=8503.8 / 8386=0.889$

2. Zn0 sample with $0.05 \mathrm{~m}$ concentration

\%Transmittance $=21455.7 / 51674.1=41.52 \%$

\%Reflectance $=7198.1 / 51674.1=13.9 \%$

Absorbance $=1-0.139=0.86=86 \%$

Emissivity $=7198.1 / 8386=0.858$

3. Zn0 sample with $0.1 \mathrm{~m}$ concentration

\%Transmittance $=26818.0 / 51674.1=51.89 \%$

\%Reflectance $=7504.3 / 51674.1=14.5 \%$

Absorbance $=1-0.1452=0.85=85 \%$

Emissivity $=7504.3 / 8386=0.894$

4. $\mathrm{Cu} / \mathrm{Ti} / \mathrm{SiO}_{2}$ sample with $0.025 \mathrm{~m}$ concentration

\%Transmittance $=35423 / 51674.1=68.55 \%$

\%Reflectance $=6952.3 / 51674.1=13.45 \%$

Absorbance $=1-0.13=0.86=86 \%$

Emissivity $=6952.3 / 8386=0.8290$ 


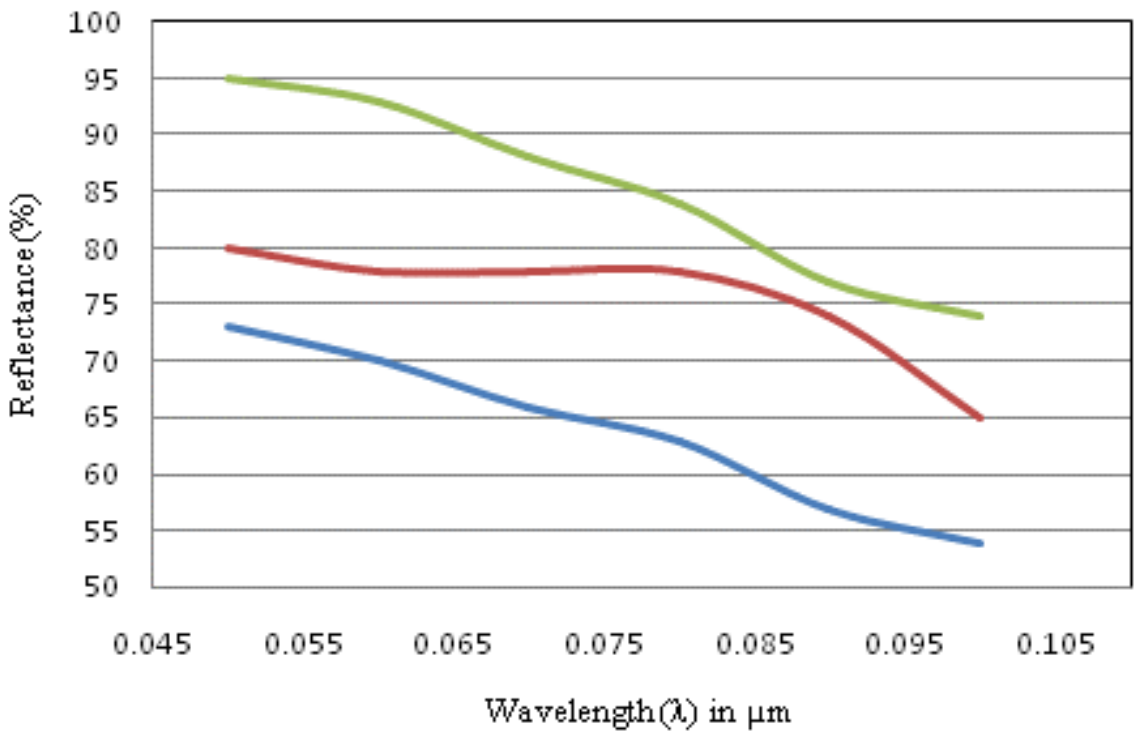

(a)

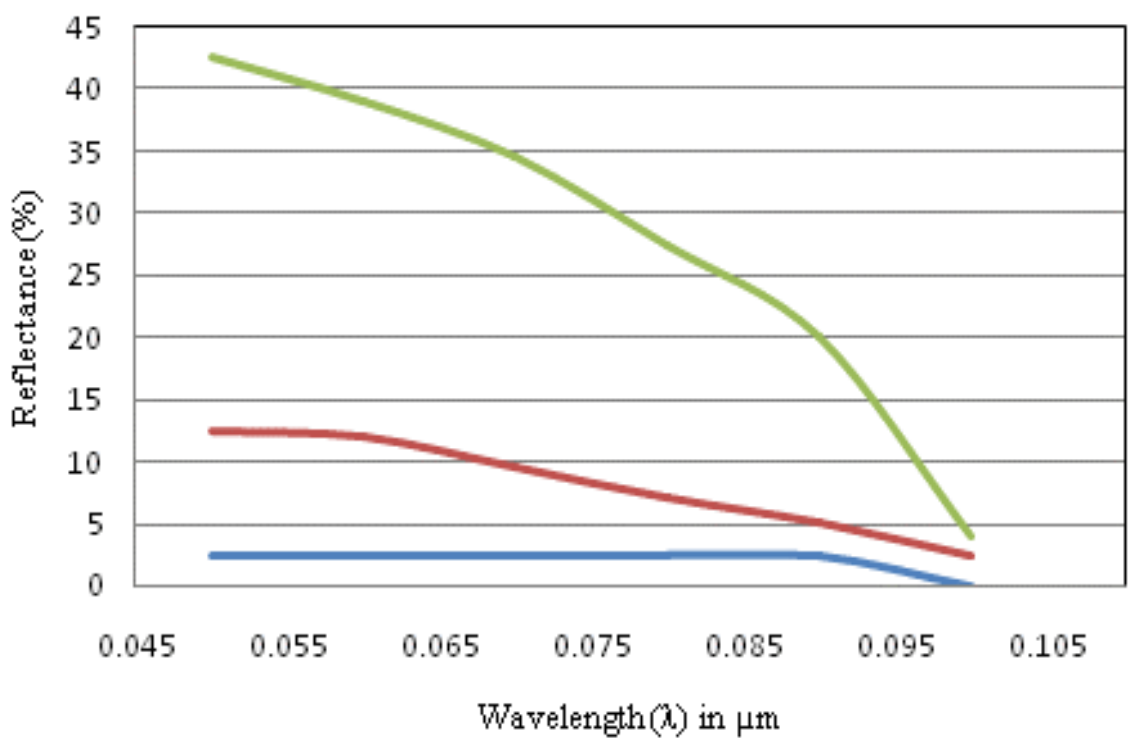

(b)

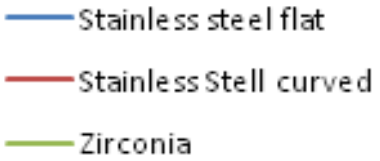

Figure 6. Reflectance measurement: (a) reflector materials (b) colored fabrics 


\section{Results and Discussions}

The experimental setup for measuring optical characteristics using integrating sphere is shown in Figure 7.The optical characteristics of various samples under test as specified in Table 2.

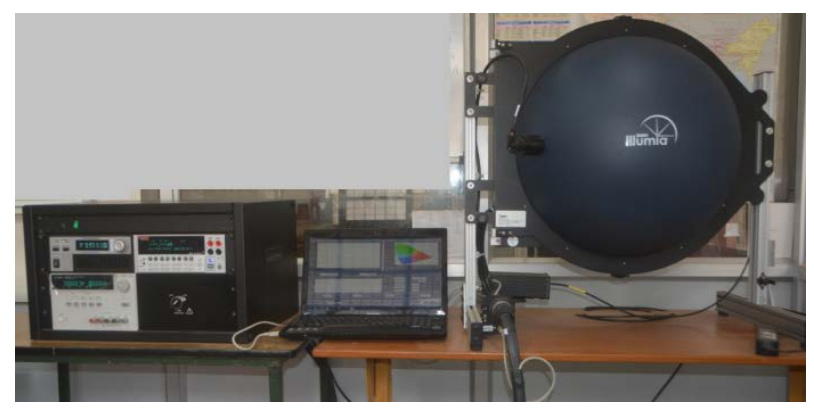

Figure 7. Experimental setup

Table 2. Materials under test and its reflectance

\begin{tabular}{|c|c|c|c|}
\hline S.no & Sample under test & Material component & \%Reflectance \\
\hline 1. & Reflector & Zirconia fibre & 93.0 \\
\hline 2. & Reflector & Stainless steel & 71.1 \\
\hline 3. & Blue green & Fabric & 43.3 \\
\hline 4. & Purple & Fabric & 11.7 \\
\hline 5. & Grey & Fabric & 2.4 \\
\hline 6. & Red & Fabric & 2.3 \\
\hline
\end{tabular}

\subsection{Testing of Coloured Fabrics and Reflector Materials}

Initially the testing was started with the reflectance measurement of reflectors which can also be essentially used as solar reflectors. Some of the colour fabrics are tested so that we can find the colors suitable for energy efficient buildings. Table 2 shows that the Zirconia fiber shows a maximum reflectance and the colored blue green fabric showed a maximum reflectance. Solar concentrators which require high reflectance of solar energy to solar materials can employ the materials of such high reflectance.

Fig 6 shows the reflector materials and colored fabrics reflectance graphically. The measured wavelength is between 650 - $700 \mathrm{~nm}$.

\subsection{Testing of Solar Cell Materials}

The various samples of solar cell coating materials are tested in the integrating sphere. Reflectance, Transmittance, Absorbance and emissivity properties are checked and tabulated for the various materials. The samples under test are tabulated in Table 3 .

The peak values obtained by measuring the optical efficiencies are tabulated in Table 3 . The tested results are those obtained without silicon wafers. The zinc oxide sample with $0.1 \mathrm{M}$ concentration exhibits $86 \%$ absorptance and 0.82 thermal emissivity.

Table 3. Tested solar cell coatings and its optical characteristics at the wavelength of 550nm

\begin{tabular}{|c|c|c|c|c|c|c|}
\hline S.No & Sample under test & Concentration(M) & \%Reflectance $(\mathrm{r})$ & \%Transmittance $(\tau)$ & Absorbance $(\alpha)$ & Thermal emissivity $(\varepsilon)$ \\
\hline 1. & ZnO & 0.025 & 16.4 & 30.9 & 83 & 0.88 \\
\hline 2. & ZnO & 0.05 & 13.9 & 33.21 & 86.1 & 0.85 \\
\hline 3. & ZnO & 0.075 & 14.5 & 31.1 & 85 & 0.89 \\
\hline 4. & ZnO & 0.1 & 13.45 & 68.5 & 86.1 & 0.82 \\
\hline
\end{tabular}

Table 4. Transmittance and reflectance for different wavelengths

\begin{tabular}{|c|c|c|c|c|c|c|c|c|}
\hline \multirow{2}{*}{ Wavelength in nm } & \multicolumn{9}{|c|}{ Zinc oxide materials concentrations in $M$} \\
\cline { 2 - 12 } & \multicolumn{2}{|c|}{$0.025 \mathrm{M}$} & \multicolumn{2}{|c|}{$0.075 \mathrm{M}$} & \multicolumn{2}{|c|}{$0.05 \mathrm{M}$} & \multicolumn{2}{c|}{$0.1 \mathrm{M}$} \\
\cline { 2 - 12 } & $r(\%)$ & $\tau(\%)$ & $r(\%)$ & $\tau(\%)$ & $r(\%)$ & $\tau(\%)$ & $r(\%)$ & $\tau(\%)$ \\
\hline 360 & 6.58 & 6.19 & 8.71 & 5.1 & 6.96 & 4.15 & 6.3 & 2.81 \\
\hline 480 & 8.3 & 12.76 & 9.28 & 18.5 & 7.76 & 11.34 & 7.1 & 49.2 \\
\hline 520 & 9.87 & 27.88 & 9.50 & 51.9 & 8.35 & 41.52 & 8.5 & 86.8 \\
\hline 550 & 16.45 & 30.9 & 14.5 & 31.1 & 13.9 & 33.21 & 13.45 & 68.5 \\
\hline 560 & 9.86 & 12.62 & 13.49 & 38.6 & 9.86 & 12.8 & 12.23 & 56.6 \\
\hline
\end{tabular}




\subsection{Optical Characteristics of Solar Cell Materials on Different Wavelengths}

The transmittance and reflectance of the different samples are calculated with respect to the wavelengths to find whether the samples absorb light of the portion of the solar spectrum. The samples under test are within the integrating sphere as specified in the methodology. The Table 4 shows the values of transmittance and reflectance on different wavelengths.

It is inferred from the Table 4 that the zinc oxide sample with $0.025 M$ shows, $400-560 \mathrm{~nm}$ which is said to be the visible region of the spectrum found to transmit some portion of the UV and useful light. Zinc oxide with $0.05 \mathrm{M}$ concentration transmits maximum visible solar light of the spectrum ranging 520-550 $\mathrm{nm}$ above which the infrared portion unsuitable for the solar energy conversion as the transmittance is decreasing as shown in Figure.8 and Figure.9.

The zinc oxide $0.075 M$ with $480-550 \mathrm{~nm}$ have the high transmittance so that it absorbs useful portion of the solar energy and eliminates infrared portion of the spectrum and the zinc oxide sample with $0.1 M$ shows maximum transmittance at the useful light region of the spectrum about $86 \%$ and starts decreasing towards the infrared portion.
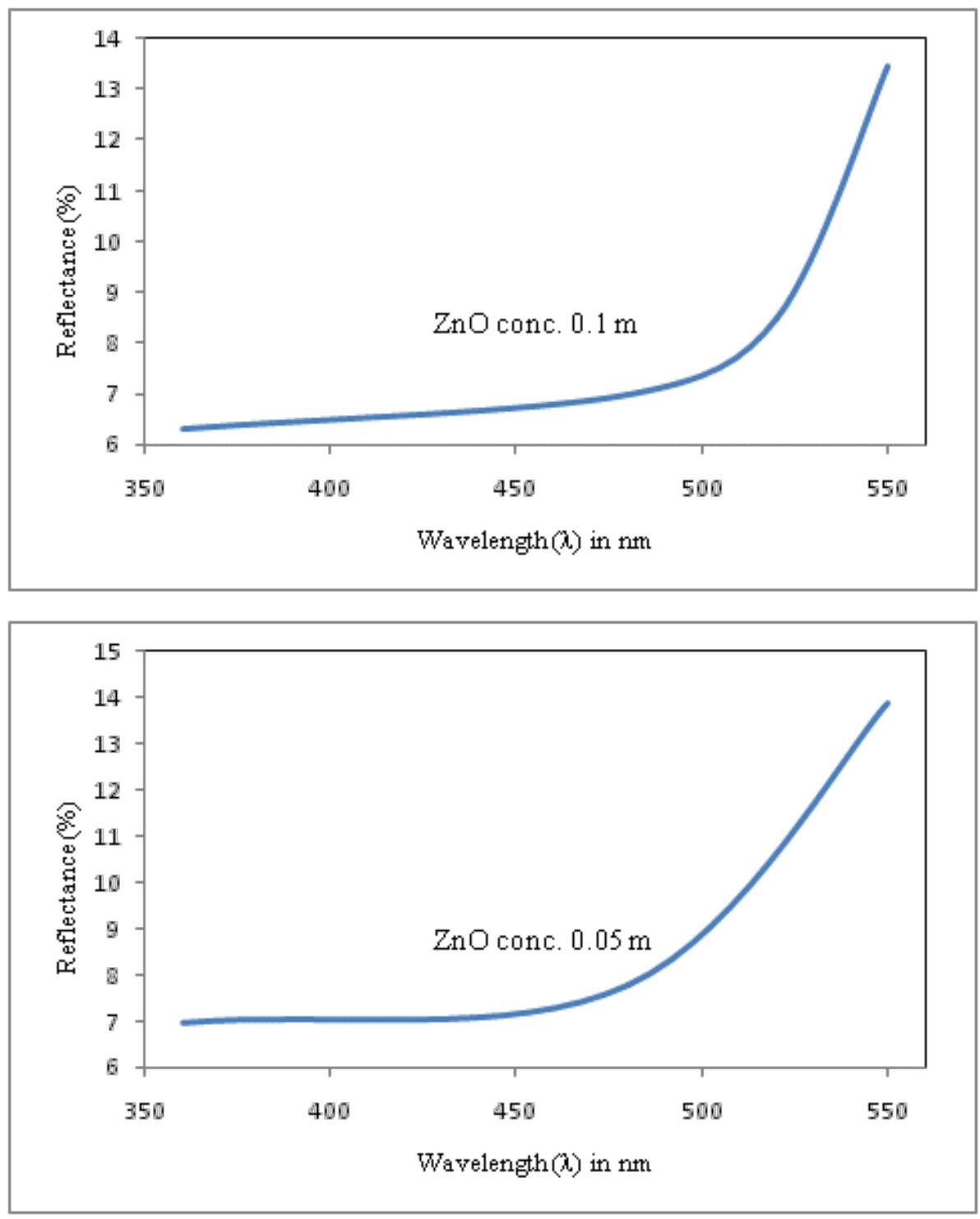

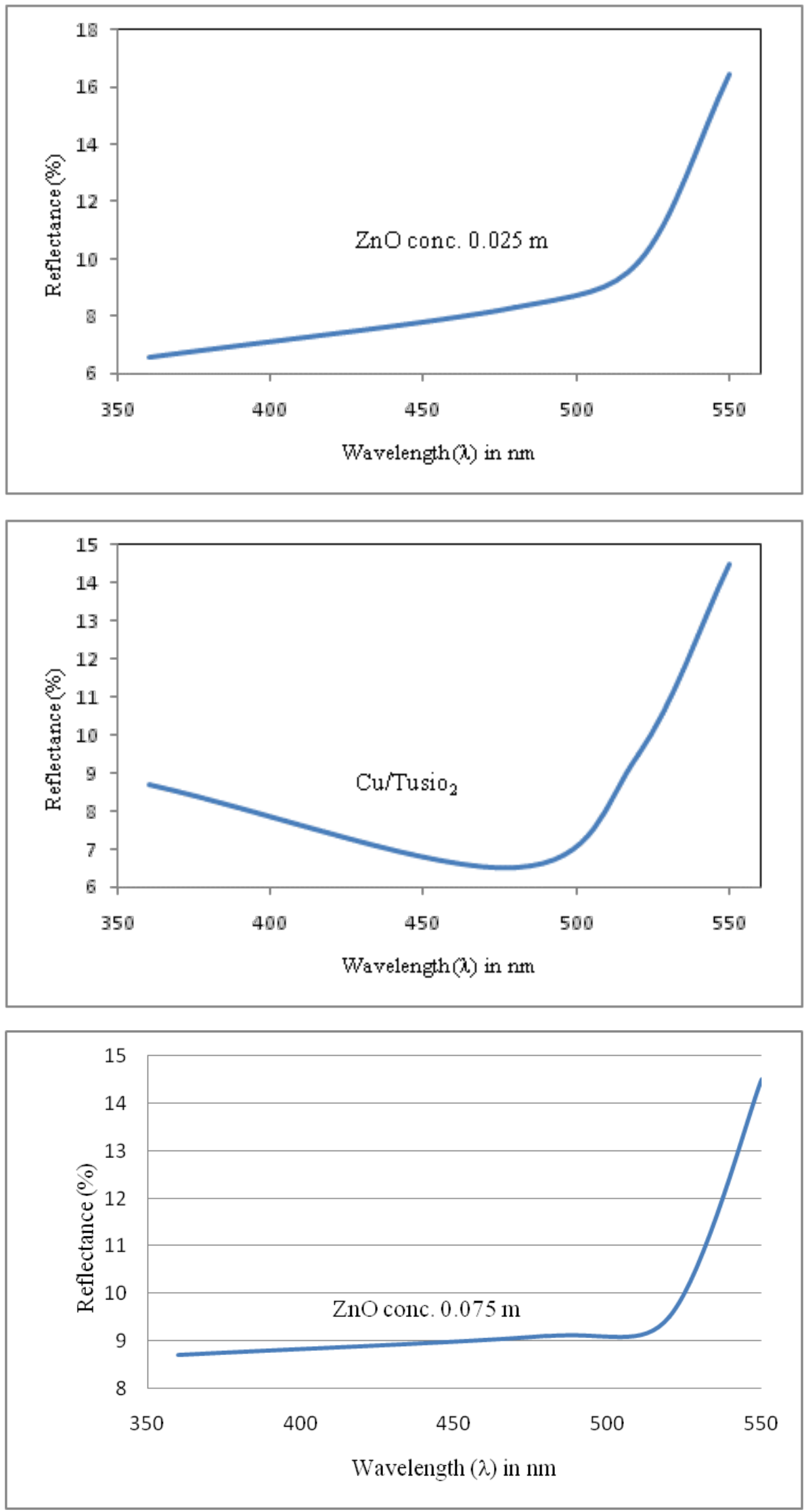

Figure 8. Reflectance of solar cell for different coatings 


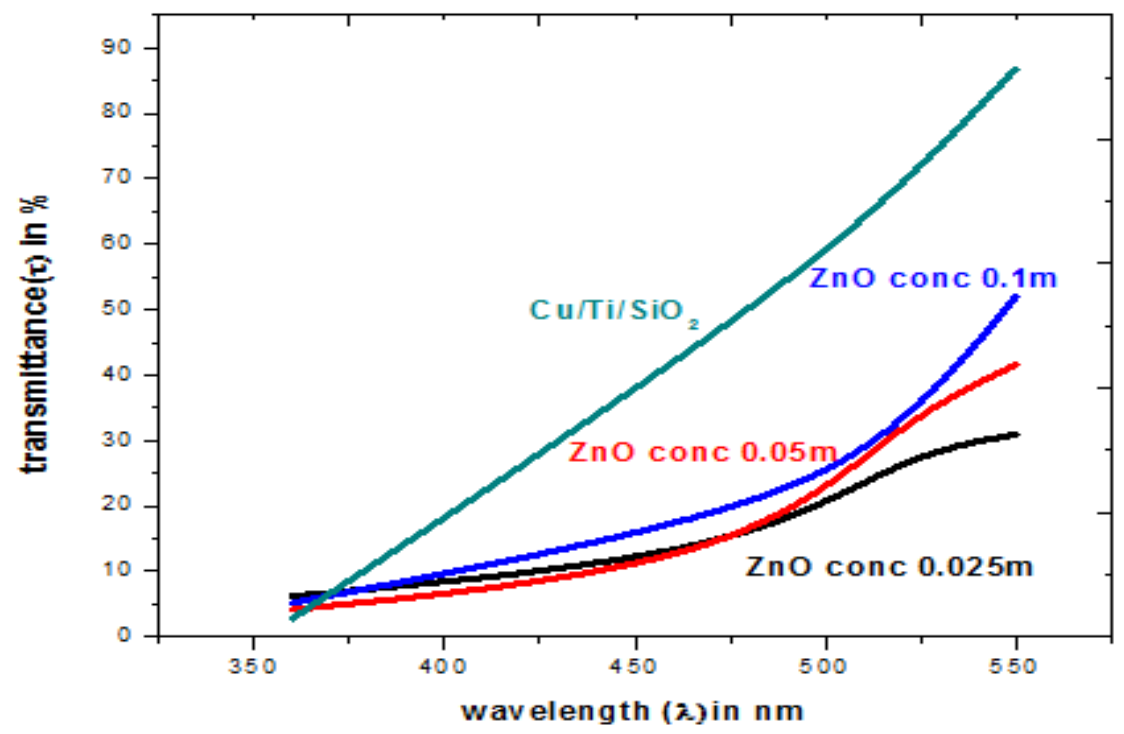

Figure 9. Transmittance of solar cell for different coatings

\subsection{Solar Cell Materials with Thin Film Silicon Wafers}

The samples are tested along with the thin film silicon cells for finding the optical properties. Thin film silicon wafers which are found to be cheap and reliable give a lesser reflectance of $6.4 \%$ and a transmittance of $77 \%$. From the tested sample is said to have lesser reflectance of $12 \%$ and transmittance higher of $79 \%$.The sample $\mathrm{ZnO}$ with $0.025 \mathrm{M}$ concentration has lesser emissivity. It is inferred that smaller the emissivity higher is the reflectance of the sample. The mathematical calculation for the silicon under test is specified below.

1. Reflectance of the silicon wafer $=$ Spectral radiance of the wafer/ spectral radiance incident on the integrating sphere $=5555.7 / 85723.0=0.064$

2. $\quad$ Absorbance $=1-0.064=0.936$

3. Radiant flux from a blackbody for the sample $=915.85 \mathrm{~W} / \mathrm{nm}$

4. Emissivity $=915.85 / 5555.7=0.164$

5. Transmittance $=1-0.064-0.164=0.772$

The integrating sphere results for the tested sample are shown in the figures below

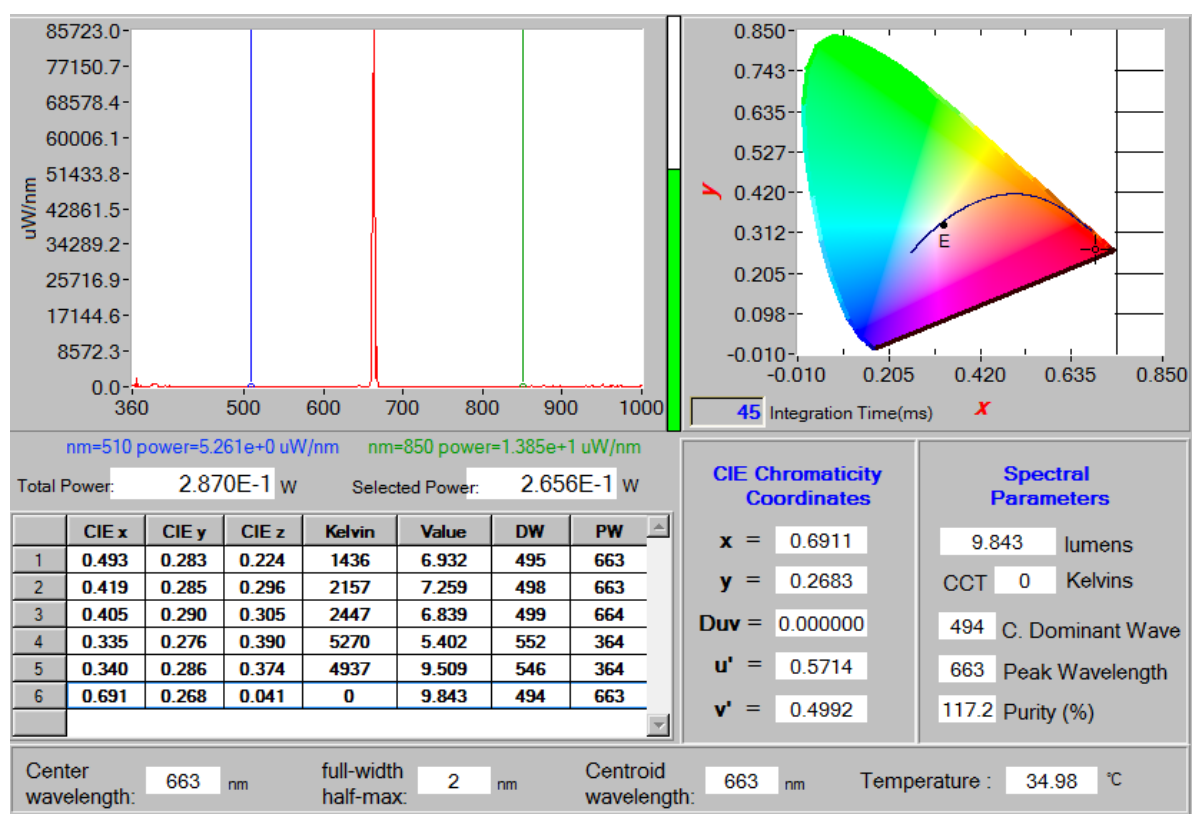

Figure 10. Incident radiance 
Figure.10 shows the incident radiance of the spectralon (integrating sphere) surface. By making the reference beam incident on the surface the radiance is found.

Figure. 11 shows the spectral radiance incident on the $\mathrm{Cu} / \mathrm{Ti} / \mathrm{SiO}_{2}$ sample. Likewise for each sample the spectral radiance and wavelengths are noted and the optical parameters are calculated respectively.

The optical characteristics of silicon thin film wafer are shown in Table 5. The transmittance of the different samples along with the silicon is represented graphically in the Figure.12 with respect to the corresponding wavelengths.

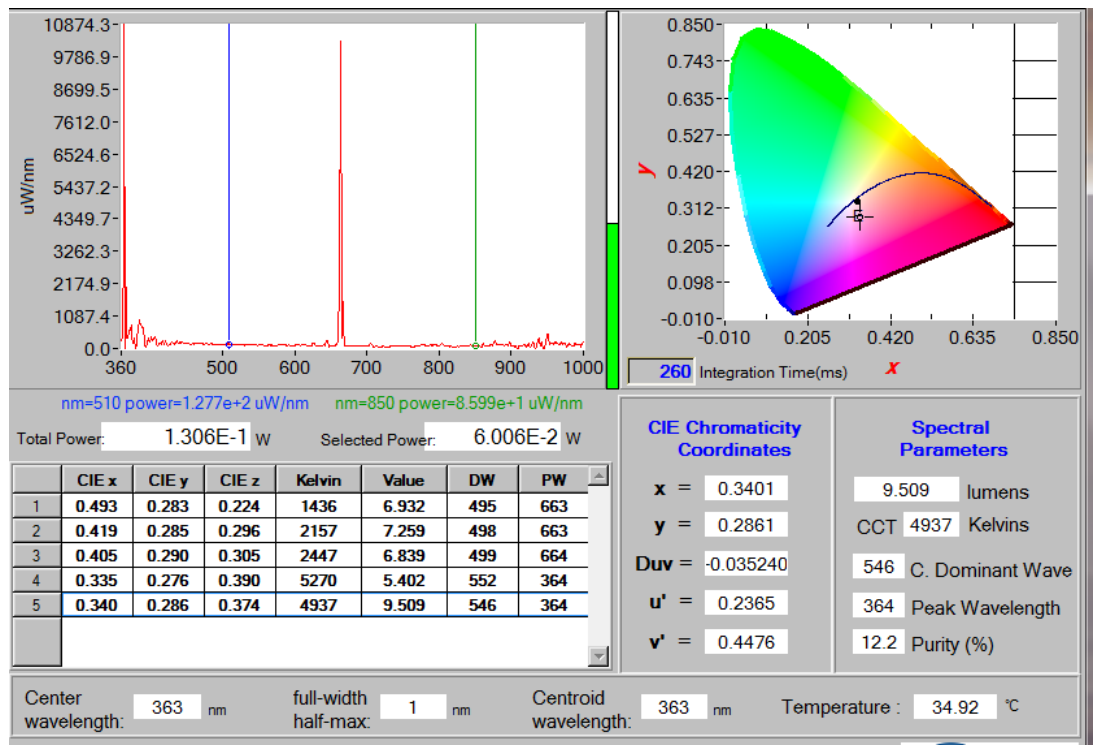

Figure 11. Radiance incident on the sample under test

Table 5. Results of tested samples with thin-film wafer

\begin{tabular}{|c|c|c|c|c|c|c|c|}
\hline S.No & Sample under test & $\begin{array}{c}\text { Concentration } \\
(\mathrm{M})\end{array}$ & $\begin{array}{c}\text { Reflectance } \\
(\mathrm{r})\end{array}$ & Transmittance $(\tau)$ & $\begin{array}{c}\text { Absorptance } \\
(\alpha)\end{array}$ & Thermal emissivity $(\varepsilon)$ & $\mathrm{W}_{\mathrm{BB}}$ \\
\hline 1. & $\mathrm{ZnO}$ & 0.025 & 0.17 & 0.75 & 0.82 & 0.070 & 1034.05 \\
\hline 2. & $\mathrm{ZnO}$ & 0.05 & 0.13 & 0.786 & 0.86 & 0.084 & 992.16 \\
\hline 3. & $\mathrm{ZnO}$ & 0.1 & 0.20 & 0.74 & 0.8 & 0.059 & 1071.53 \\
\hline 4. & $\mathrm{Cu} / \mathrm{Ti} / \mathrm{SiO}_{2}$ & 0.025 & 0.12 & 0.80 & 0.87 & 0.090 & 981.17 \\
\hline
\end{tabular}

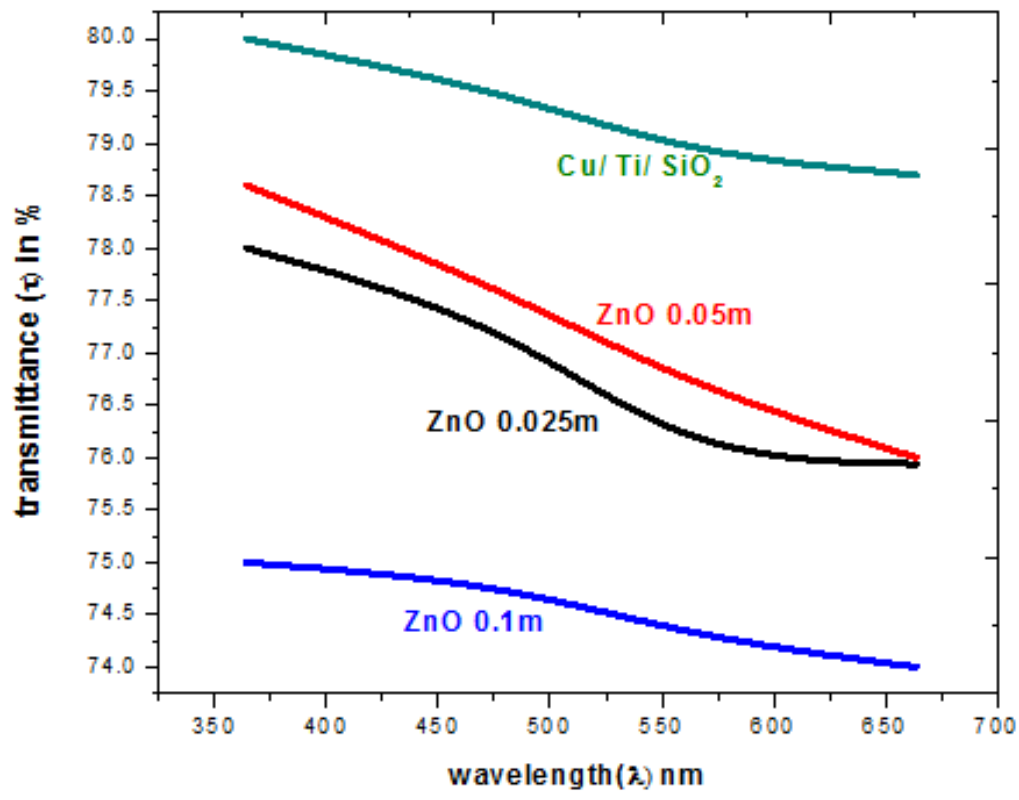

Figure 12. Transmittance with respect to the wavelength 
From the Figure.12 It is observed that nearly on the shorter wavelength of the solar spectrum the sample $\mathrm{Cu} / \mathrm{Ti} / \mathrm{SiO}_{2}$ sample shows $80 \%$ transmittance, $\mathrm{ZnO} 0.05 \mathrm{M}$ concentration sample shows $78.6 \%$ transmittance. $\mathrm{ZnO}$ $0.025 \mathrm{M}$ concentration sample shows about $78 \%$ transmittance and the $\mathrm{ZnO} 0.1 \mathrm{M}$ concentration with 75\% transmittance.

\section{Conclusions}

The reflectance and transmittance characteristics of the various solar cell materials have been analyzed. From the tested solar cell materials with thin-film silicon the $\mathrm{Cu} / \mathrm{Ti} / \mathrm{SiO}_{2}$ shows transmittance of $68.55 \%$ and an absorbance value of $86 \%$ and $\mathrm{ZnO}$ with concentration of $0.1 \mathrm{M}$ shows transmittance of $75 \%$ and an absorbance value of $80 \%$. Then the different solar cell materials are patched with the thin-film wafer to find the most optically efficient solar cell material. The transmittance value has been found to be improved to $79 \%$ and lesser reflectance of $12 \%$. The integrating sphere used offers uniform detection of reflectance even when the sample has different content. The future work can be carried out by further investigations with different silicon wafers and the future solar cell materials can be investigated such as indium tin oxide, cadmium coatings etc.

\section{Acknowledgement}

This work was supported in part by the AICTE, New Delhi under Research promotion scheme vide sanction number 20/AICTE/RIFD/RPS (POLICY-IV) 36/2012-13.

\section{REFERENCES}

[1] R.Z. Wang, X.Q.Zhai, Development of solar thermal technologies in China, Energy, vol.35, pp.4407-4416, 2010.

[2] Young Tae Chae, et. al., Building energy performance evaluation of building integrated photovoltaic (BIPV) window with semi-transparent solar cells, Sol.Energy, Vol. 129, pp.217-227, 2015.

[3] Emiliano Carnieloa, Michele Zinzib, Aldo Fanchiottia, On the solar reflectance angular dependence of opaque construction materials and impact on the energy balance of building components, Energy procedia, vol.48, pp.1244-1253, 2013

[4] Peter Cendula et. al, Analysis of Optical Losses in a Photoelectrochemical Cell: A Tool for Precise Absorptance Estimation, Advanced Function Materials, vol.28, no.1, 2018.

[5] Liqing Zheng, et. al, Angular solar absorptance and thermal stability of Mo-SiO2double cermet solar selective absorber coating, Sol. Energy,vol.115, pp. 341-346, 2015.

[6] T. Bostrom, E.Wackelgard, G.Westin, Solution-chemical derived Nickel-alumina coatings for thermal solar absorbers, Sol. Energy, vol. 74, pp.497-503, 2003.

[7] Philipp Good et.al, Spectral reflectance, transmittance, and angular scattering of materials for solar concentrators, Sol. Energy Mater. Sol.Cells, vol.144, pp.509-522, 2016.

[8] Romain Carron et.al, Refractive indices of layers and optical simulations of $\mathrm{Cu}(\mathrm{In}, \mathrm{Ga}) \mathrm{Se} 2$ solar cells, Science and Technology of Advanced Materials, pp.1-44, 2018.

[9] T.N.Anderson, M.Duke, J.K.Carson, The effect of colour on thethermal performance of building integrated solar collectors, Sol. Energy Mater. Sol.Cells, vol. 94, pp.350 354, 2010.

[10] Ruihua Yang et.al, Optical properties and thermal stability of coloured solar selective absorbing coatings with double-layer antireflection coatings, Sol. Energy, vol.125, pp.453-459, 2016.

[11] Ronnen Levinsona et.al, Methods of creating solar-reflective non-white surfaces and their application to residential roofing materials, Sol. Energy Mater. Sol.Cells, vol. 91, pp.304-314, 2017.

[12] Yangwei $\mathrm{Wu}$ et. al, Coloured solar selectiveabsorbing coatings with metal $\mathrm{Ti}$ and dielectric AlN multilayer structure, Sol. Energy Mater. Sol. Cells, vol.115, pp. 145150, 2015.

[13] Dechun Zhu, Shuxi Zhao, Chromaticity and optical properties of coloured and black solar-thermal absorbing coatings, Sol. Energy Mater. Sol.Cells, Vol. 94, pp.16301635, 2010

[14] A. Roos, Use of an integrating sphere in solar energy research, Sol. Energy Mater. Sol.Cells, vol.30, pp.77-94, 1993. 